\title{
Vibrational Relaxation and Bond Dissociation of Excited Methylpyrazine in the Collision with HF
}

\author{
Hee-Gyun Oh, Jongbaik Ree, "Sang Kwon Lee, and Yoo Hang Kim ${ }^{\dagger}$ \\ Department of Science Education, Chomam National University, Gwangin 500-757, Korea. "E-mail: jbree@chonnamac.hr \\ "Department of Chemistry and Center for Chemical Dynamics, Inha University, Incheon 402-751, Korea \\ Received Jume 26,2006
}

\begin{abstract}
Vibrational relaxation and competitive $\mathrm{C}$-I $\mathrm{I}_{\text {methyl }}$ and $\mathrm{C}$-I $\mathrm{I}_{\text {ring }}$ bond dissociations in vibrationally excited methylpyrazine in the collision with IFF have been studied by use of classical trajectory procedures. The energy lost by the vibrationally excited methylpyrazine upon collision is not large and it increases slowly with increasing total vibrational energy content between 20,000 and $45,000 \mathrm{~cm}^{-1}$. $\Lambda$ bove the energy content of $45,000 \mathrm{~cm}^{-1}$, however, energy loss decreases. The temperature dependence of energy loss is negligible between 200 and $400 \mathrm{~K}$, but above $45,000 \mathrm{~cm}^{-1}$ the energy loss increases as the temperature is raised. Energy transfer to or from the excited methyl C-II bond occurs in strong collisions with IF, that is, relatively large amount of translational energy is transferred in a single step. On the other hand, energy transfer to the ring C-II bond occurs in a series of small steps. When the total energy content $E_{1}$ of methylpyrazine is sufficiently high, either or both C-II bonds can dissociate. The C-II probability. The dissociation of the ring C-II bond is not the result of the direct intermolecular energy flow from the direct collision between the ring C-II and IF but the result of the intramolecular flow of energy from the methyl group to the ring C-II stretch.
\end{abstract}

Key Words : Collision-induced, Intramolecular, Methylpyrazine, HF, Dissociation

\section{Introduction}

The collision-induced vibrational energy transfer of vibrationally excited polyatomic molecules has been the subject of continuing interest over 30 years. ${ }^{1-11}$ An important characteristic of vibrational relaxation in a large molecule is intramolecular energy flow, which plays a key role in bond dissociation. Recent studies ${ }^{9-18}$ show that when the excited molecule is a large organic molecule, the average amount of energy transfer per collision is not very large. The average energy transfer per collision between the vibrationally highly excited benzene and a noble gas atom is known to be about $30 \mathrm{~cm}^{-1}$, which is much smaller than benzene derivatives such as hexafluorobenzene or other hydrocarbons such as toluene and methylpyrazine..$^{5.819-22}$ For example, for hexafluorobenzene $+\mathrm{Ar}$, the measured value of the mean energy transfer per collision determined by the ultraviolet absorption method is $-330 \mathrm{~cm}^{-1}, 20$ whereas the calculated value using quasiclassical trajectory methods at $300 \mathrm{~K}$ is $-150 \mathrm{~cm}^{-1}$.23 For toluene $+\mathrm{Ar}$, the amount of energy transfer is about $-200 \mathrm{~cm}^{-1} .^{21}$ Collision-induced energy transfer between a highly excited polyatomic molecule and a bath gas plays a relevant role in studies of chemical reactions. Among such large molecules, toluene and methylpyrazine (MP) are particularly attractive molecules for studying collision-induced intramolecular energy flow and bond dissociation because of the presence of both methyl and ring $\mathrm{CH}$ bonds, presenting an intriguing competition among them. Pyrazine and its derivatives form an important class of compounds present in many natural flavors and complex organic molecules. The 2-methylpyrazine is used in flavors in food. Yoder $e t a l$ investigated the vibrational energy transfer in collisions between MP and argon by means of quasiclassical trajectory calculations. ${ }^{24}$ For pyrazine $+\mathrm{CO}_{2}$, Grigoleit et al. showed that $\mathrm{V}-\mathrm{V}$ energy transfer is almost completely negligible. ${ }^{22}$

The purpose of this paper is to study the collision-induced dynamics of vibrationally highly excited MP interacting with HF using quasiclassical trajectory calculations. The knowledge of collisional energy transfer processes responsible for the relaxation and activation of vibrationally highly excited molecules is essential for a detailed description of many molecular reaction dynamics. The main questions we address in this work are: (1) How does the magnitude of energy loss by MP vary as a function of the total vibrational energy content initially stored in MP? (2) How does the energy flow between the pyrazine ring $\mathrm{C}-\mathrm{H}$ and methyl group C-H stretches? (3) What is the C-H bond dissociation dynamics and mechanism? Trajectory calculations are a useful tool in the study of collisional energy transfer. They allow the controlled study of the effects of potential surface, vibrational energy, collision duration, and temperature on the dynamics of energy exchange. Using the results obtained in the calculations, we discuss the time scale for bond dissociation, the relaxation of the excited $\mathrm{CH}$ vibration, and the time evolution of collision-induced intramolecular energy flow from the highly excited $\mathrm{CH}$ vibration. Finally, we elucidate the nature and mechanism of competition between methyl $\mathrm{CH}$ mode and ring $\mathrm{CH}$ mode in transferring energy to or from the incident molecule. 


\section{Interaction Model and Energies}

The vibrational coordinates of MP and model for the MPHF interaction are defined in Figure I, where all carbon and nitrogen atoms, the ring hydrogen atoms and the incident molecule are assumed to be coplanar. In Figure $1 \mathrm{~b}$, we define the interaction coordinates between the methyl $\mathrm{CH}$ bond and the adjacent ring $\mathrm{CH}$ bond of a non-rotating $\mathrm{MP}$ with the incident $\mathrm{HF}$ molecule. The $\mathrm{CH}_{\text {ring }}$ bond is in the

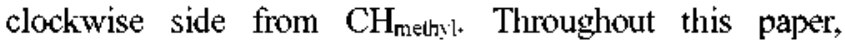
$\mathrm{CH}_{\text {methyl }}$ and $\mathrm{CH}_{\text {ring }}$ will denote these two bonds. The angle $\theta$ is the angle of incidence defined in Figure $\mathrm{Ib}$, the angle at which the line connecting the centers of mass of MP and HF crosses the line connecting the hydrogen atoms $\mathrm{H}_{\text {ring }}$ and $\mathrm{H}_{\text {melty }}$.

The important step in developing an interaction potential model is to start with physically reasonable interaction potential energies, which are dependent upon the pertinent collision coordinates. The interaction energies needed to describe the collision of HF with MP must contain terms

(a)

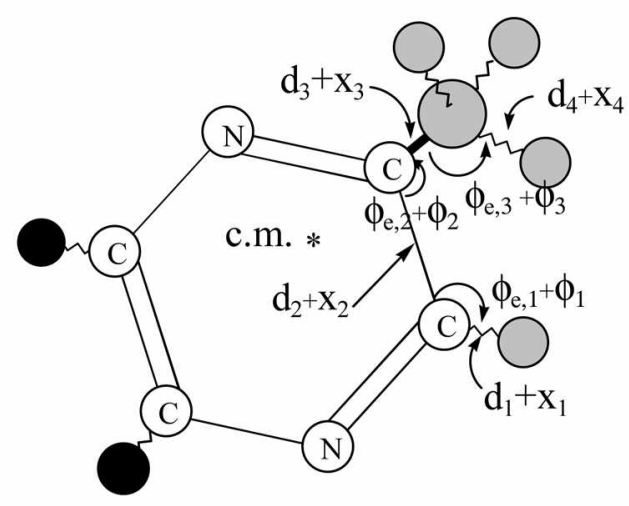

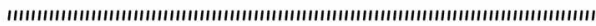

(b)

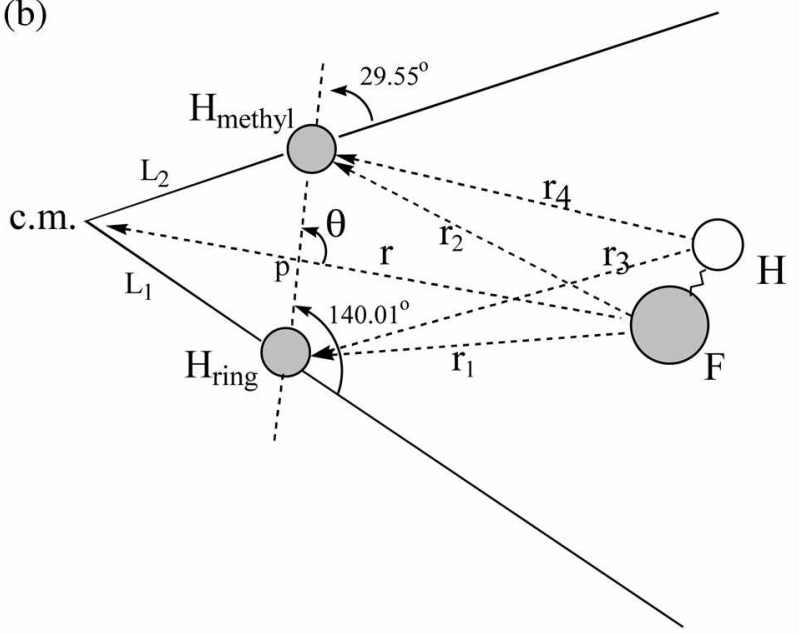

Figure 1. Collision model. (a) The vibrational stretching and bending coordinates included in the model. All carbon, nitrogen and ring $H$ atoms are coplanar. The star denotes the center-of-Inass (cin) of MP. (b) The relative coordinate between HF and the c.m. of MP $(r)$, the F-lo-they distance $\left(r_{1}\right)$, the F-to- $\mathrm{H}_{\text {mectry }}$ distance $(r)$, Hto- $\mathrm{H}_{\mathrm{rug}}$ distance $\left(r_{3}\right)$ and $\mathrm{H}-\mathrm{to}-\mathrm{H}_{\text {nichlyl }}$ distance $\left(r_{4}\right)$ are shown. responsible for the coupling of the relative motion with the ring $\mathrm{C}-\mathrm{H}$ stretch and methyl group $\mathrm{C}-\mathrm{H}$ stretch as well as the coupling between the stretches and bends. We first introduce the interatomic distances $r_{1}-r_{4}$ in the interaction model as defined in Figure 1b. The interatomic distances can be expressed in terms of the instantaneous coordinates of the $\mathrm{C}$ $\mathrm{H}_{\text {methyl }}$ bond, $\mathrm{C}-\mathrm{CH}_{\text {methyl }}$ bond, $(\mathrm{C}-\mathrm{C})_{\text {ring }}$ bond, $\mathrm{C}-\mathrm{H}_{\text {ring }}$ bond, $\mathrm{CCH}_{\text {methyl }}$ bend, $\mathrm{CCC}_{\text {neethyl }}$ bend, $\mathrm{CCH}_{\text {ring }}$ bend and $\mathrm{HF}$ bond. That is, $r_{i}=r_{i}\left(r, x_{1}, x_{2}, x_{3}, x_{4}, \phi_{1}, \phi_{2}, \phi_{5}, x_{1 T,}, \theta\right)$ for $i=1-4$. Here $r$ is the distance between the c.m. of HF and the c.m. of MP describing the relative motion of the collision system. The values of equilibrium bond distances and other potential parameters except HF are listed in Table 1. ${ }^{17,24,35}$ Each bond length will be denoted by $\left(d_{i}+x_{i}\right)$, where $x_{i}$ is the displacement of the $i$ th bond length from its equilibrium value $d_{\mathrm{i}}$. Similarly, we express each bending coordinate as $\left(\phi_{\mathrm{ej}}+\right.$ $\phi_{\mathrm{j}}$ ), where $\phi_{\mathrm{j}}$ is the displacement of the $j$ th bending vibration from the equilibrium angle $\phi_{\mathrm{ej}}$.

The F-to- $\mathrm{H}_{\text {ring }}\left(r_{1}\right), \mathrm{F}$-to- $\mathrm{H}_{\text {nethy }}\left(r_{2}\right), \mathrm{H}$-to- $\mathrm{H}_{\text {ring }}\left(r_{3}\right)$ and $\mathrm{H}$-to$\mathrm{H}_{\text {metry }}\left(r_{4}\right)$ interatomic distances can be obtained as

$$
\begin{aligned}
r_{1}= & {\left[y_{1}^{2}+\left(d_{H F}+x_{H F}\right)^{2} \mu_{H}^{2}-2 y_{1}\left(d_{H F}+x_{H F}\right) \mu_{H} \cos \left(\phi-\rho_{1}\right)\right]^{1 / 2} } \\
r_{2}= & {\left[\nu_{2}^{2}+\left(d_{H F}+x_{H F}\right)^{2} \mu_{H}^{2}-2 y_{2}\left(d_{H F}+x_{H F}\right) \mu_{H} \cos \left(\phi+\rho_{2}\right)\right]^{1 / 2} } \\
r_{3}= & {\left[v_{1}^{2}+\left(d_{H F}+x_{H F}\right)^{2} \mu_{F}^{2}-2 y_{1}\left(d_{H F}+x_{H F}\right) \mu_{F}\right.} \\
& \left.\times \cos \left(\pi-\phi+\rho_{1}\right)\right]^{1 / 2} \\
r_{4}= & {\left[v_{2}^{2}+\left(d_{H F}+x_{H F}\right)^{2} \mu_{F}^{2}-2 \nu_{2}\left(d_{H F}+x_{H F}\right) \mu_{F}\right.} \\
& \left.\times \cos \left(\pi-\phi-\rho_{2}\right)\right]^{1 / 2}
\end{aligned}
$$

where, $\phi$ is the rotational angle of HF measured clockwise from the line $r$ connecting the centers of mass of methylpyrazine and HF, $\mu_{\mathrm{H}}=m_{\mathrm{H}} /\left(m_{\mathrm{II}}+m_{\mathrm{\Gamma}}\right), \mu_{\mathrm{F}}=m_{\Gamma} /\left(m_{\mathrm{II}}+m_{\mathrm{\Gamma}}\right), x_{\mathrm{IT}}$ is the displacement of the HF from its equilibrium bond

\begin{tabular}{|c|c|c|c|c|}
\hline Stretches & $\begin{array}{l}\mathrm{C}-\mathrm{H}_{\text {ring }} \\
(i=1)\end{array}$ & $\begin{array}{c}\mathrm{C}-\mathrm{C} \\
(i=2)\end{array}$ & $\begin{array}{l}\mathrm{C}-\mathrm{CH}_{3} \\
(i=3)\end{array}$ & $\begin{array}{c}\mathrm{C}-\mathrm{H}_{\text {mettys }} \\
(i=4)\end{array}$ \\
\hline Dissociation energy $D_{o, i}(\mathrm{eV})^{a}$ & $4.770^{4}$ & $5.637^{a}$ & $4.336^{4}$ & $3.903^{4}$ \\
\hline Bond Distance $d_{i}(\AA)^{h}$ & $1.088^{b}$ & $1.400^{h}$ & $1.497^{b}$ & $1.089^{b}$ \\
\hline Frequency $\left(\mathrm{cm}^{-1}\right)^{-i}$ & $3068^{i t}$ & $1494^{c}$ & $1208^{\circ}$ & $3003^{c}$ \\
\hline Range parameter $b_{1}(\AA)$ & 0.555 & 0.482 & 0.523 & 0.515 \\
\hline Bends & $\phi_{1}$ & $\phi 2$ & $\phi \S$ & \\
\hline Frequency $\left(\mathrm{cm}^{-1}\right)$ & 1312 & 344 & $1460^{\circ}$ & \\
\hline Bond angle $(0)$ & $120.4^{b}$ & $121.7^{h}$ & $109.3^{b}$ & \\
\hline Force constant $\left(J \mathrm{rad}^{-2} \times 10^{-18}\right)$ & $0.521^{4}$ & $0.912^{a}$ & $0.667^{\prime \prime}$ & \\
\hline
\end{tabular}
distance $d_{\mathrm{iT}}$ and $y_{1}$ and $y_{2}$ are distances between $\mathrm{H}_{\text {ring }}$ and $\mathrm{H}_{\text {metby }}$ and the c.m. of $\mathrm{HF}$, respectively, and defined as

$$
v_{1}=\left[(r-z)^{2}+A^{2}-2 A(r-z) \cos \theta^{1 / 2},\right.
$$

Table 1. Potential and Spectroscopic constants

"Reference 24. "Reference 25. "same as those for toluene (Ref. 17). daverage of the three ring $v_{\text {cr m }}$ modes, $3085,3067,3053 \mathrm{~cm}^{-1}$. "average of the three mett $y$ v $v_{\text {in }}$ modes, $3037,3007,2965 \mathrm{~cm}^{-1}$ 


$$
y_{2}=\left[(r-z)^{2}+B^{2}+2 B(r-z) \cos \theta\right]^{12},
$$

Here,

$$
\begin{aligned}
& z=c_{1} \sin \left(140^{\circ}\right) / \sin \theta, A=c_{2} \sin \left(\theta-29.55^{\circ}\right) / \sin \theta, \\
& B=c_{1} \sin \left(140^{\circ}-\theta\right) / \sin \theta \\
& \rho_{1}=\sin ^{-1}\left[\frac{A}{r_{1}} \sin \theta\right], \rho_{2}=\sin ^{-1}\left[\frac{B}{r_{2}} \sin (\pi-\theta)\right] \\
& c_{1}=\left[q^{2}+\left(d_{1}+x_{1}\right)^{2}+2 \theta\left(d_{1}+x_{1}\right) \cos \left(\phi_{1}-\lambda / 2-\eta\right)^{1 / 2},\right. \\
& c_{2}=\left[G^{2}+\left(d_{4}+x_{4}\right)^{2}-2 G\left(d_{4}+x_{4}\right) \cos \left(107.6^{\circ}+\phi_{3}-\xi\right)^{1 / 2},\right. \\
& G=\left[0.8987+\left(d_{3}+x_{3}\right)^{2}-1.896\left(d_{3}+x_{3}\right) \cos \phi_{2}\right]^{1 / 2}, \\
& q=\left[d^{2}-0.894 d \cos \left(60^{\circ}+\lambda\right)+0.1998\right]^{1 / 2}, d=1.400 \AA, \\
& \xi=\sin ^{-1}\left[0.948 \sin \phi_{2} / G\right], \\
& \lambda=2 \sin ^{-1}\left[x_{2} /\left(3^{1 / 2} d\right)\right], \\
& \eta=\sin ^{-1}\left[0.447 \sin \left(60^{\circ}+\lambda\right) / q\right] .
\end{aligned}
$$

Here all distances are in $\AA$ and $z$ is distance between the c.m. of MP and point " $p$ " between $\mathrm{H}_{\text {ring }}$ and $\mathrm{H}_{\text {methyl. }}$.

The above distances and relations detemine the coupling of the translation to vibrational motions (i.e., the coupling of $r$ with $x_{1}, x_{2}, x_{3}, x_{4}, \phi_{1}, \phi_{2}, \phi_{3}$, and $x_{\Pi \pi}$ ).

The overall interaction energy is the sum of the Morsetype intermolecular terms, Morse-type stretching terms and the hammonic bending terms of MP, and Morse-type stretching term of $\mathrm{HF}$,

$$
V=\sum\left(r_{a}\right)+U_{s}\left(x_{i}\right)+U_{b}\left(\phi_{i}\right)+U_{H F}\left(x_{H F}\right)
$$

Where,

$$
\begin{aligned}
& U\left(r_{\alpha}\right)=D\left[e^{\left(r_{\alpha i \alpha}-r_{\alpha}\right) / a}-2 e^{\left(r_{\alpha \alpha}-r_{\alpha}\right) / 2 a}\right], \alpha=1-4 \\
& U_{s}\left(x_{i}\right)=\sum D_{i}\left[1-e^{-x_{i} / b_{j}}\right]^{2}, i=1-4 \\
& U_{b}\left(\phi_{j}\right)=1 / 2 \sum k_{j} \phi_{j}^{2}, j=1-3 \\
& U_{H F}\left(x_{H F j}\right)=D_{H F}\left[1-e^{-x_{H F} / b_{H F}}\right]^{2} .
\end{aligned}
$$

$$
\begin{aligned}
& I_{j} d^{2} \phi(t) / d t^{2}=-\frac{\partial}{\partial \phi_{i}} V\left(r, x_{1}, \ldots, x_{4}, \phi_{1}, \ldots, \phi_{3}, x_{\mathrm{HT}}, \theta\right), j=1-3 \\
& \mu_{H F} d^{2} x_{H F}(\mathrm{t}) / d t^{2}=-\frac{\partial}{\partial x_{H F}} V\left(r, x_{1}, \ldots, x_{4}, \phi_{1}, \ldots, \phi_{3}, x_{\mathrm{IT}}, \theta\right)
\end{aligned}
$$

where $\mu$ is the reduced mass of the collision system, $\mu_{i}$ is the reduced mass associated with the $i$ th stretch and $I_{j}$ is the moment of inertia of the $j$ th bend. $\mu_{\mathrm{Hr}}$ is the reduced mass of $\mathrm{HF}$. We use the standard numerical routines ${ }^{29.30}$ to integrate these equations for the initial conditions at $t=t_{0}$ and their conjugate quantities $\left.(d / d t) r\left(t_{0}\right),(d / d t) x_{(}\left(t_{0}\right),(d / d t) \phi_{\left(t_{0}\right)}\right)$, and $(d / d t) x_{H F}\left(t_{0}\right)$, where the derivatives are evaluated at $t=t_{0}$. From our preliminary calculations, we know that the interaction near $\theta=87^{\circ}$ plays the dominant role in promoting energy loss or $\mathrm{C}-\mathrm{H}$ bond dissociation through inter- or intramolecular energy transfer. ${ }^{10.11}$ Thus, in all collision systems considered here, the incident atom approaches the center of mass of MP in the $\theta=87^{\circ}$ direction, where the $\mathrm{CH}_{\text {nethyly }}-\mathrm{HF}$ and $\mathrm{CH}_{\text {ring- }} \mathrm{HF}$ interactions are very close to each other and where energy transfer is most efficient. ${ }^{10}$

\section{Numerical Procedures}

We solve the equations of motion for the relative motion, 4 stretches and 3 bends of MP, and HF vibration using the DIVPAG double-precision routine of the IMSL library ${ }^{29.30}$ to describe the time evolution of bond distances, bond angles, and vibrational energies, as well as the relative coordinate for the model system. We sample 40,000 trajectories for each vibrational energy content, $E_{\mathrm{T}}$, at $300 \mathrm{~K}$, where the sampling includes determining collision energies $(E)$ chosen from the Maxwell distribution. To study the temperature dependence of energy transfer, the calculation will also be carried out at $T=200$ and $400 \mathrm{~K}$. The initial conditions for solving the equations of motion for the relative motion and the displacements and phases for the vibrational motions in the interaction zone are given in Ref. 10. We vary the initial vibrational energies of the $\mathrm{C}-\mathrm{H}_{\text {ring }}$ and $\mathrm{C}-\mathrm{H}_{\text {nethy }}$ bonds (i.e, $i$ $=1$ and 4) systematically, while maintaining the rest of the vibrational motions in the ground state. Each vibrational phase is a random number $\delta_{\mathrm{i}}=2 \pi \mathrm{s}_{\mathrm{i}}$ with flat distribution of $\mathrm{S}_{\mathrm{i}}$ in the interval $(0,1)$. The initial separation between the centers of mass of MP and $\mathrm{HF}$ is set as $15 \AA$, and trajectories are terminated when the separation reaches $50 \AA$ after they passed through the closest distance of approach. The integration was performed with a stepsize of $0.169 \mathrm{fs}$, which is one-tenth the period of the largest frequency, the ring $\mathrm{CH}$ vibration, and is small enough to ensure energy conservation to at least five significant figures along a trajectory. We have also confirmed that the numerical procedure allows the trajectories to be successfully backintegrated.

From the dynamics study, we can decide when the $\mathrm{C}-\mathrm{H}$ distance exceeds a critical value, at which time dissociation is assumed to occur. The occurrence of dissociative events can be readily recognized by studying the time evolution of the methyl (or ring) $\mathrm{CH}$ bond trajectory and the $\mathrm{CH}_{\text {nethyl }}$ (or

$$
\mu_{i} d^{2} x_{i}(\mathrm{t}) / d t^{2}=-\frac{\partial}{\partial x_{i}} V\left(r, x_{1, \ldots,} x_{4}, \phi_{1}, \ldots, \phi_{5}, x_{\mathrm{II} F}, \theta\right), i=1-4
$$


$\mathrm{CH}_{\text {ring }}$ ) vibrational energy, as well as all intermediate modes in the interaction zone, which are conduits for the energy flow. The bond dissociation probability is defined as the ratio of the number of dissociative trajectories to the total number of trajectories sampled, which is 40,000 , in each run.

We define the ensemble-averaged energy transfer $\langle\Delta E\rangle=$ $\left\langle E_{\text {linal }}-E\right\rangle$, the difference between the final and initial translational energies of HF. Thus, a positive value of $\langle\Delta E\rangle$ represents the ensemble-averaged energy loss by MP, a V $\rightarrow$ $\mathrm{T}$ energy transfer process. The ensemble average of the vibrational energy of each mode consists of kinetic and potential energy terms. The dissociation of a highly excited bond occurs when the bond gains energy from the incident molecule ( $\mathrm{T} \rightarrow \mathrm{V}$ pathway) or from adjacent bonds through intramolecular energy flow or both.

\section{Results and Discussion}

Dependence of Energy Loss on the Total Vibrational Energy Content. In Figure 2, we show the dependence of ensemble averaged energy loss on the total vibrational energy content $E_{\mathrm{T}}$ at $300 \mathrm{~K}$. The smallest value of $E_{\mathrm{T}}$ considered in this figure is $13,492 \mathrm{~cm}^{-1}$ or $1.673 \mathrm{eV}$, which corresponds to the vibrational energies of $\mathrm{C}-\mathrm{H}_{\text {nethy }}$ and $\mathrm{C}$ $\mathrm{H}_{\text {rine }}$ being $3,250 \mathrm{~cm}^{-1}(0.403 \mathrm{eV})$ and $10,242 \mathrm{~cm}^{-1}(1.270$ $\mathrm{eV})$, respectively. That is, both bonds are simultaneously 3.5 $\mathrm{eV}$ below the dissociation threshold of each bond. At this total vibrational energy content, the energy loss is $271 \mathrm{~cm}^{-1}$ or $0.0337 \mathrm{eV}$. For pyrazine-Ar collision, Yoder et al. have shown that the average vibrational energy transfer is 204 $\mathrm{cm}^{-1}$ for $E_{\mathrm{T}}=25,000 \mathrm{~cm}^{-1}$ at $300 \mathrm{~K}$, which is comparable to our value for the similar collision system. ${ }^{24}$ Below $E_{\mathrm{T}}=$ $45,000 \mathrm{~cm}^{-1}$, the magnitude of energy loss increases gradually with increasing total vibrational energy content. As shown in Figure 2, for example, when $E_{\mathrm{T}}$ is raised from $13,492 \mathrm{~cm}^{-1}$ to $45,752 \mathrm{~cm}^{-1},-<\Delta E>$ increases from 271 $\mathrm{cm}^{-1}$ to $778 \mathrm{~cm}^{-1}$, which are nearly $2 \%$ of $E_{\mathrm{T}}$. The latter $E_{\mathrm{T}}$ value, $45,752 \mathrm{~cm}^{-1}$ corresponds to $\mathrm{C}-\mathrm{H}_{\text {methyl }}$ and $\mathrm{C}-\mathrm{H}_{\text {ring }}$ having the initial vibrational energies of $19,380 \mathrm{~cm}^{-1}$ and $26,372 \mathrm{~cm}^{-1}$, respectively, which are $1.5 \mathrm{eV}$ below the dissociation threshold of each bond. As the total energy content continues to increase, however, $-\langle\Delta E\rangle$ now decreases gradually, and then finally begins to increase again

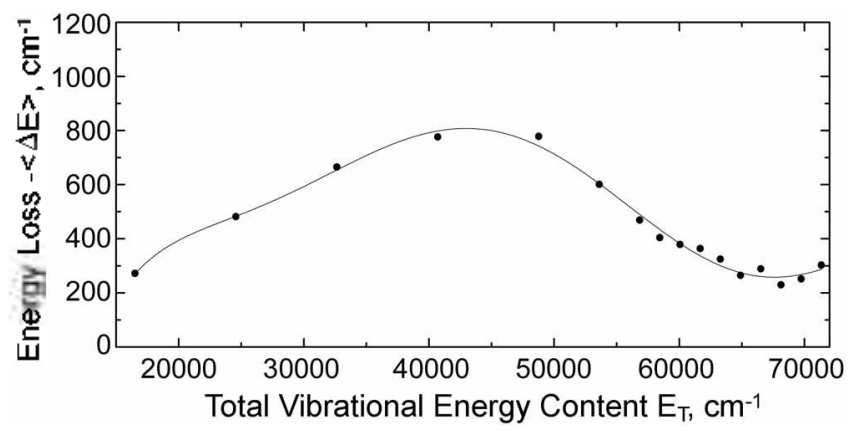

Figure 2. Energy loss against the total vibrational energy content $E_{\mathrm{T}}$ at $T=300 \mathrm{~K}$.

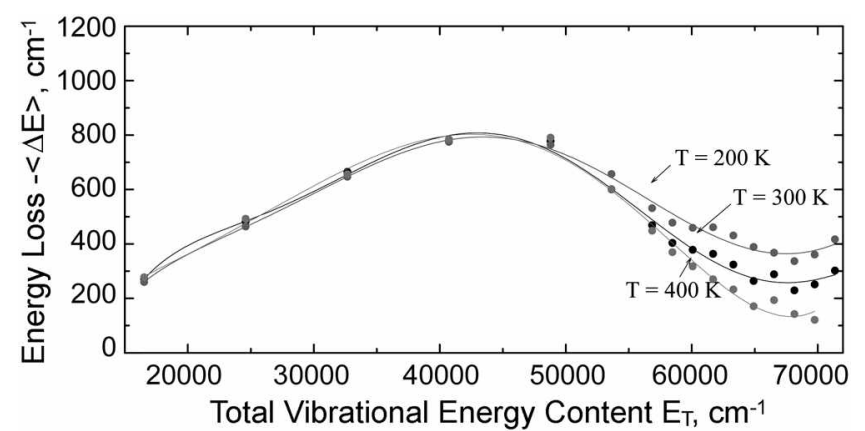

Figure 3. Dependence of energy loss on the total vibrational energy

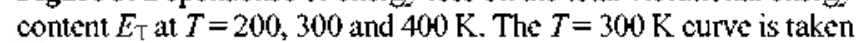
from Figure 2.

slightly from $E_{\mathrm{T}}=65,000 \mathrm{~cm}^{-1}$. This trend is very similar to toluene-HF system. " In latter system, however, toluene gains energy from incident $\mathrm{HF}$ near the dissociation thresohld. In the study on the toluene- $\mathrm{N}_{2}$ system at room temperature, ${ }^{9}$ Wright, Sims and Smith found that there is gradual increase in the magnitude of energy loss when the range of the total vibrational energy content is from 5,000 $\mathrm{cm}^{-1}$ to about $40,000 \mathrm{~cm}^{-1}$ for toluene excited directly by adsorption of photons at $266 \mathrm{~nm}$. A slow variation of $-<\Delta E>$ with increasing $E_{\mathrm{T}}$ shown in Figure 2 has been known to be the general behavior for the relaxation of toluene by rare gases and diatomic molecules such as $\mathrm{N}_{2}$ in experimental and theoretical studies. ${ }^{9.27 .31}$ Furthermore, the experimental work with excited toluene formed via photoisomerization of cycloheptatriene at $308 \mathrm{~nm}$ shows the appearance of a maximum value at higher $E_{\mathrm{T}},{ }^{9}$ which is nearly the same $E_{\mathrm{T}}$ at which the maximum appears in the present study.

We also consider the variation of MP's energy loss with $E_{\mathrm{T}}$ at 200 and $400 \mathrm{~K}$ in Figure 3. They are very close to that at $300 \mathrm{~K}$ up to $50,000 \mathrm{~cm}^{-1}$, which means that the temperature dependence is insignificant. Such a negligible temperature dependence has also been noted in experimental studies. ${ }^{9}$ But, from $50,000 \mathrm{~cm}^{-1}$ toward dissociation threshold the energy loss decreases further as the temperature is increased. Thus, the gross feature of the $E_{\mathrm{T}}$ dependence of $\left.-<\Delta E\right\rangle$ at these temperatures for the initially excited MP molecules is that the amount of energy loss increases with increasing vibrational excitation which exhibits negligible temperature dependence. The increase of energy loss is weak up to a moderate amount of the vibrational energy content. However, as $E_{\mathrm{T}}$ continues to increase, energy loss decreases gradually and then again increases slightly when the total vibrational energy content is increased toward the dissociation threshold. Furthernore, the temperature dependence, even though it is weak, begins to show up near the dissociation threshold.

Bond Dissociation. We now discuss the collision-induced $\mathrm{C}-\mathrm{H}$ dissociation of the highly excited MP molecule. We plot the dissociation probabilities at $300 \mathrm{~K}$ in Figure 4. Here we take as before both $\mathrm{C}-\mathrm{H}$ bonds have their initial vibrational energies which are below their respective 


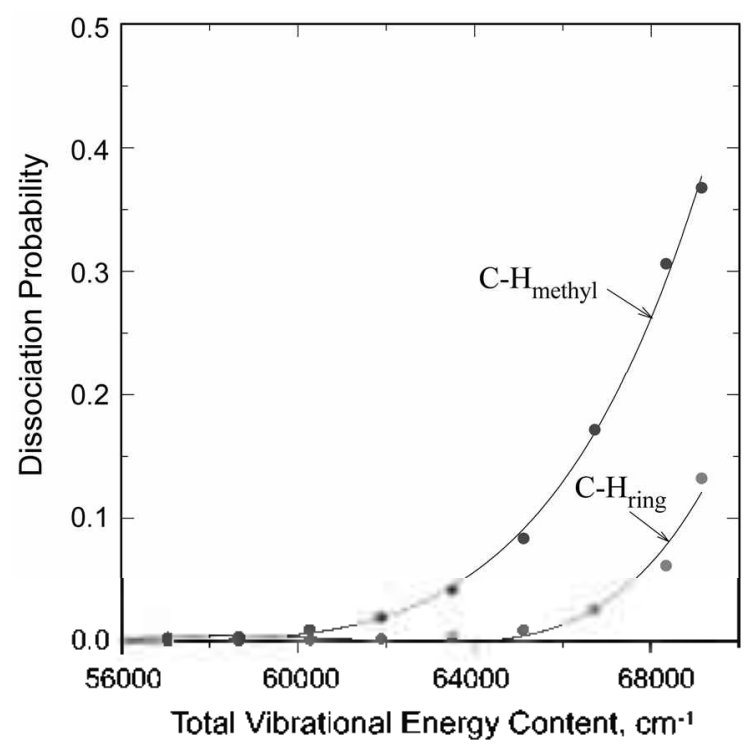

Figure 4. Dissociation probabilities of $\mathrm{C}-\mathrm{H}_{\text {niellyyl }}$ and $\mathrm{C}-\mathrm{H}_{\mathrm{run}}$ bonds against the total vibrational energy content $E_{\mathrm{T}}$ at $T=300 \mathrm{~K}$.

dissociation threshold by the same amount. When each of them is $0.8 \mathrm{eV}$ or $6,452 \mathrm{~cm}^{-1}$ below the threshold, the total vibrational energy content is $57,044 \mathrm{~cm}^{-1}$ above the zero point energy with $32,018 \mathrm{~cm}^{-1}$ in $\mathrm{C}-\mathrm{H}_{\text {ring }}$ and $25,026 \mathrm{~cm}^{-1}$ in $\mathrm{C}-\mathrm{H}_{\text {nethy. }}$ At this energy the dissociation probabilities are $P_{\text {C-Imentyl }}=0.0026$ and $P_{\text {C-IIring }}=0.0005$. Here dissociation probabilities are very small because a large amount of energy has to deposit in either one of the $\mathrm{C}-\mathrm{H}$ bonds. From Figure 2 we note that the ensemble-averaged energy loss by MP for $E_{\mathrm{T}}=57,044 \mathrm{~cm}^{-1}$ is only $378 \mathrm{~cm}^{-1}$ or $0.0469 \mathrm{eV}$. Since the $\mathrm{C}-\mathrm{H}_{\text {nethyl }}$ (or $\mathrm{C}-\mathrm{H}_{\text {ring }}$ ) bond is $6,452 \mathrm{~cm}^{-1}$ below its dissociation threshold and the molecule loses only $378 \mathrm{~cm}^{-1}$, this bond has to gain at least $6,830 \mathrm{~cm}^{-1}$ from $\mathrm{C}-\mathrm{H}_{\text {ring }}$ (or $\mathrm{C}$ $\mathrm{H}_{\text {me1syl }}$ ) through intramolecular energy redistribution to dissociate. This fact explains the very low dissociation probabilities. As shown in Figure $4, P_{C \text {-Himetyl is always }}$ greater than $P_{C \text {-Hring }}$ for the total vibrational energy content chosen such that both bonds are below their respective dissociation threshold by the same amount of energy at 300 $\mathrm{K}$. When the total energy content is increased from 57,044 $\mathrm{cm}^{-1}$ toward the dissociation threshold, the probabilities rise very rapidly. When $E_{\mathrm{T}}$ is as high as $68,335 \mathrm{~cm}^{-1}$, which corresponds to each bond's vibrational energy only $0.1 \mathrm{eV}$ below the dissociation threshold, the dissociation probabilities are now $P_{C \text {-Hmethy }}=0.306$ and $P_{\text {C-Hring }}=0.062$. Such large values indicate that the vibrational motions of a highly excited molecule can be readily perturbed by the incident collision partner and the molecule needs only a small amount of energy to dissociate. The ensemble-averaged energy loss by nondissociative MP in this case is $302 \mathrm{~cm}^{-1}$. In such a highly excited molecule, both $\mathrm{C}-\mathrm{H}$ bonds can dissociate. However, the probability of simultaneous dissociation of $\mathrm{C}-\mathrm{H}_{\text {methyl }}$ and $\mathrm{C}-\mathrm{H}_{\text {ring }}$ is quite small. For example, it is only 0.0005 when $E_{\mathrm{T}}$ is as high as $68,335 \mathrm{~cm}^{-1}$, which shows that the majority of dissociative events involve breaking only one $\mathrm{C}-\mathrm{H}$ bond.
The lifetime distribution for the $\mathrm{CH}_{\text {ring }}$ bond dissociation displayed in Figure 5a' shows an induction period of $=0.2$ ps before the distribution rises sharply to the maximum at $\tau=$ $0.55 \mathrm{ps}$, beyond which it decreases exponentially. In contrast to this process, the lifetime distribution for $\mathrm{CH}_{\text {metryl }}$ bond dissociation shows no induction period with most dissociative events occurring immediately after the collision with HF (see Figure 5a), when the energy imparted to $\mathrm{H}_{\text {nethy }}$ rapidly flows to $\mathrm{CH}_{\text {methy }}$ leading to the bond dissociation. The distribution decreases sharply between $\tau=0.1$ and 0.3 $\mathrm{ps}$, the dependence being nonexponential. The behavior of Figure $5 \mathrm{a}$ which is quite different from Figure $5 \mathrm{a}^{\prime}$ represents the collisional transfer of translational energy into the $\mathrm{CH}_{\text {methyl }}$ stretch.

When the initial excitation is lowered, a larger amount of energy has to flow from $\mathrm{CH}_{\text {methyl }}$ to $\mathrm{CH}_{\text {ring }}$ to cause the $\mathrm{CH}_{\text {ring }}$ dissociation, the process which is less efficient than the higher excitation case. In fact, when each of the two $\mathrm{CH}$ bonds is $0.9 \mathrm{eV}$ below the threshold, $P_{\text {Ciring }}=0$, but the extent of $\mathrm{CH}_{\text {nethyl }}$ dissociation is still significant.

The disparity in the two induction periods reveals a subtle aspect of the collision dynamics in which two very different energy transfer mechanisms operate, which can be discussed by comparing the results of Figure $5 \mathrm{a}$ with those of a
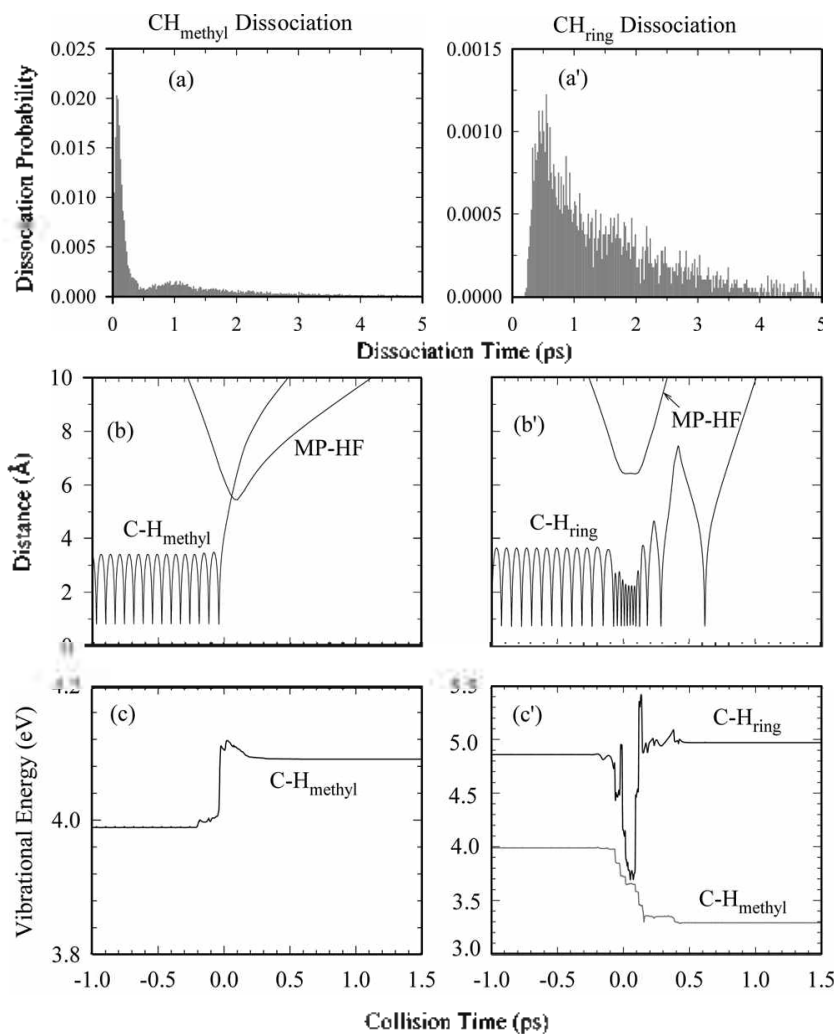

Figure 5. Dependence of the $\mathrm{CH}$ dissociation probability on the dissociation time $\tau$ for (a) the $\mathrm{CH}_{\text {methyl }}$ bond and (a') $\mathrm{CH}_{\text {yug }}$ bond at $E_{\mathrm{T}}=68,335 \mathrm{~cm}^{-1}$. Time cvolution of the collision trajectory and the $\mathrm{CH}$ bond trajectory for (b) $\mathrm{CH}_{\text {wnchyl }}$ and (b') $\mathrm{CH}_{\text {rny }}$ at $E_{\mathrm{T}}=68,335$ $\mathrm{cm}^{-1}$. The same scale is used for both figures. Time evolution of the $\mathrm{CH}$ vibrational energies for (c) $\mathrm{CH}_{\text {niellyyl }}$ and $\left(\mathrm{c}^{+}\right) \mathrm{CH}_{\mathrm{ring}}$, Note that the energy scales are different. However, the time scale is the same for (b), (b'), (c) and (c'). 
representative reactive collision (Figs. $5 \mathrm{~b}$ and $5 \mathrm{c}$ ) for the $\mathrm{CH}_{\text {mehyl }}$ dissociation and the results of Figure $5 \mathrm{a}^{\prime}$ with those of a representative reactive collision (Figs. $5 b^{\prime}$ and $5 c^{\prime}$ ) for the $\mathrm{CH}_{\text {ring }}$ dissociation. The time evolution of the $\mathrm{CH}_{\text {nethyl }}$ bond trajectory is shown in Figure 5b, where the large amplitude motion of the excited bond suddenly diverges as $\mathrm{HF}$ approaches. The time evolution of the $\mathrm{CH}_{\text {methyl vibra- }}$ tional energy shows a sharp energy jump, the bond gaining nearly $0.13 \mathrm{eV}$ (see Figure 5(c)), which exceeds the amount needed to dissociate. The energy jump occurs in a single step over a short time period of $\approx 50 \mathrm{fs}$, which is approximately one period of the excited $\mathrm{CH}_{\text {methyl }}$ bond stretching. From a significant change in the slope of the collision trajectory before and after collision shown in Figure $5 \mathrm{~b}$, we notice that the energy jump is mainly detemined by $T \rightarrow V$ energy transfer from $\mathrm{HF}$.

For the trajectory representing the $\mathrm{CH}_{\text {rine }}$ dissociation shown in Figure $5 b^{\prime}$, the $\mathrm{CH}_{\text {ring }}$ bond trajectory takes nearly $0.7 \mathrm{ps}$ before diverging. During this period, which corresponds to the induction period shown in Figure 5a', energy flows from $\mathrm{CH}_{\text {methyl }}$ to $\mathrm{CH}_{\text {ring, }}$, i.e., the energy imparted to $\mathrm{H}_{\text {mehyl }}$ flows to $\mathrm{H}_{\text {ring }}$ since direct $\mathrm{T} \rightarrow \mathrm{V}$ energy transfer to the $\mathrm{CH}_{\text {ring }}$ bond in the $\mathrm{HF}-\mathrm{CH}_{\text {ring }}$ interaction is inefficient. The time scale of the energy buildup in $\mathrm{CH}_{\text {ring }}$ closely matches that of the energy loss in $\mathrm{CH}_{\text {neithil, }}$ as they are linked by the energy flow path (see Figure $5 \mathrm{c}^{\prime}$ ). For the representative trajectory depicted in Figure $5 \mathrm{c}^{\prime}$, the $\mathrm{C}-\mathrm{H}_{\text {methyl }}$ bond loses $0.7 \mathrm{eV}$ while the $\mathrm{C}-\mathrm{H}_{\text {ring }}$ bond gains $0.13 \mathrm{eV}$. Therefore, the overall energy loss during this collision is $0.57 \mathrm{eV}$ $\left(\approx 4,600 \mathrm{~cm}^{-1}\right)$. Note that the overall energy loss $\Delta E$ for the entire ensemble of all $E_{\mathrm{T}}=68,355 \mathrm{~cm}^{-1}$ is only $300 \mathrm{~cm}^{-1}$. Once a sufficient amount of energy deposits in the $\mathrm{CH}_{\text {ring }}$ bond, the dissociation can occur rapidly, as shown by the large values of dissociation probability between $\tau=0.5$ and $2.0 \mathrm{ps}$ (see Figure $5 \mathrm{a}^{\prime}$ ). It is important to notice in Figure $5 \mathrm{c}^{\circ}$ that the activation of $\mathrm{CH}_{\text {ring }}$ occurs in a series of small energy transfer steps, the variation which is significantly different from the one-step excitation behavior of the $\mathrm{CH}_{\text {methyl }}$ activation seen in Figure $5 \mathrm{c}$.

For a more comprehensive study one might include the main frame, that is, inner vibrations of the methylpyrazine molecule in addition to the reaction-zone vibrations considered in this study. As a matter of fact, this enlarged model has already been employed in the similar collision systems, toluene $+\mathrm{Ar}^{17.18}$ and toluene $+\mathrm{HF}^{11}$

\section{Concluding Comments}

We have studied $\mathrm{CH}$ bond dissociation and energy transfer, both intermolecular and intramolecular, in the MP-HF collision system using classical trajectory procedures. The collision system consists of the interaction zone, where the incident molecule interacts with both $\mathrm{CH}_{\text {nethyl }}$ and $\mathrm{CH}_{\text {ring }}$ bonds.

Energy loss is found to be small, but slowly increases with the total vibrational energy content initially stored in the C$\mathrm{H}_{\text {nethyl }}$ bond and the adjacent $\mathrm{C}-\mathrm{H}_{\text {ring }}$ bond. Energy loss takes a maximum value as the energy content increases toward the dissociation threshold. Although the extent of energy lost by excited MP via $\mathrm{V} \rightarrow \mathrm{T}$ energy transfer is not large, intramolecular vibrational energy flow between the $\mathrm{C}-\mathrm{H}$ bonds is efficient and takes place on a subpicosecond time scale. When the vibrational energies of both $\mathrm{C}-\mathrm{H}$ bonds are set initially below the dissociation threshold by the same amount, the dissociation probability of $\mathrm{C}-\mathrm{H}_{\text {nethy }}$ bond is found to be larger than that of $\mathrm{C}-\mathrm{H}_{\text {ring }}$ bond. Collisioninduced bond dissociation and energy transfer processes in MP are mainly controlled by the $\mathrm{CH}_{\text {methy }} \mathrm{l}-\mathrm{HF}$ interaction.

Further excitation of the $\mathrm{CH}_{\text {methyl }}$ bond toward the dissociation threshold as well as the relaxation of the highly excited $\mathrm{CH}_{\text {methyl }}$ involve a large amount of energy transfer $(\gg k T)$ occurring essentially in a single-step process in strong collisions. The $\mathrm{CH}_{\text {methyl }}$ bond dissociation occurs without an induction period. The dissociation of the highly excited $\mathrm{CH}_{\text {ring }}$ bond is a result of intramolecular energy flow from $\mathrm{CH}_{\text {methyl }}$ with the $\mathrm{CH}_{\text {ring }}$ bond acquiring its energy for dissociation in a series of small steps over a period longer than $0.5 \mathrm{ps}$. Unlike the $\mathrm{CH}_{\text {methy }}$ dissociation, this reaction thus occurs after a considerable induction period.

Acknowledgments. This work was financially supported by research fund of Chonnam National University in 2004. The computational part of this work was supported by "the 6th Supercomputing Application Support Program" of the KISTI (Korea Institute of Science and Technology Information).

\section{References}

1. Transfer and Storage of Energy by Molectles; Burnett. G. M.; North, A. M., Eds.; Wiley: New York, 1969; Vol. 2.

2. Smith. I. W. M. In Gas Kinefics and Energy Transfers; specialist Periodical Reports; Chemical Society, Burlington House: London, 1977; Vol. 2, pp 1-57.

3. Yardley, J. T. Introduction to Molecular Energy Transfer; Academic: New York, 1980.

4. Lendvay, G.; Schatz, G. C. J. Phys. Chem. 1990, 94, 8864; 1994, 98, 6530; Lendvay, G.; Schatz, G. C. J. Chem. Phys. 1993, 98, 1034; Lendvay, G.; Schatz, G. C.; Harding, L. B. Faraday Discuss. $1995,102,389$.

5. Toselli, B. M.; Barker, J. R. J. Chem. Phys. 1992, 97, 1809.

6. Clarke, D. L.; Oref, I.; Gilbert, R. G J. Chem. Phys. 1992, 96, 5983.

7. Orr, B. J. In Actwances in Chemical Kinetics and Dynamics. Vol. 2: Vibrational Entergy Transfer Inolving Large and Snall Molectles; Barker, J. R., Ed.; JAI Press: Greenwich, CT, 1995; p 21.

8. Clary, D. C.; Gilbert, R. G; Bernshtein, V; Otef, I. Faraday. Discuss, 1995, 102, 423.

9. Wright, S. M. A.; Sims, I. R.; Smith, I. W. M. J. Phys. Chem. A $2000,104,10347$.

10. Ree. J.; Kim, Y. H.; Shin, H. K. J. Chem. Phys. 2002. 116. 4858.

11. Ree, J.; Kim, S. H.; Lee, T. H.; Kim, Y. H. Bull. Kor. Chem. Soc. $2006,27,495$.

12. Lim, K. F. J. Chem. Phys. 1994, 101, 8756.

13. Catlett, D. L. Jr.; Parmenter, C. S.; Pursell, C. J. J. Phys. Chem. 1994, 98,$3263 ; 1995,99,7371$.

14. Shin, H. K. J. Phys, Chetn, A 1999, $103,6030$.

15. Shin, H. K. J. Phys, Chem, A 2000, $104,6699$.

16. Nilsson, D.; Nordholm, S. J. Chem. Phys, 2002, 116, 7040. 
17. Ree, J.; Kim, Y. H.; Shin, H. K. Chem. Phss. Leff. 2004, $394,250$.

18. Ree, J.; Chang, K. S.; Kim, Y. H.; Shin, H. K. Bull. Kor. Chent. Soc. 2003, 24, 1223; Ree, J.; Kim. Y. H.; Shin. H. K. Bull. Kor. Chem. Soc. 2005, 26, 1269.

19. Yerram, M. L.; Brenner, J. D.; King, K. D.; Barker, J. R. J. Phys. Chem. 1990, 94, 6341.

20. Damm. M.; Hippler, H.; Olschewski, H. A.; Troe, J.; Willner, J. Z. Phys. Chem. N. F. 1990, 166, 129.

21. Toselli, B. M.; Brenner, J. D.; Yerram, M. L.; Chin, W. E.; King, K. D.; Barker, J. R. J. Chem. Phys, 1991, 95, 176.

22. Grigoleit, U.; Lenzer, T.; Luther, K.; Mülzel, M.; Takahara, A. Phys. Chem. Chem. Phys, 2001, 3,2191.

23. Lenzer, T.; Luther, K.; Troe, J.; Gilbert, R. G.; Lim, K. F. J. Chem. Phys. 1995, 103, 626.
24. Yoder, L. M.; Barker, J. R. J. Phss. Chem. A 2004, 104, 10184.

25. Endrédi, H.; Billes, F.; Keresztury, G. J. Mol. Sfructure (Theochem) 2004, 677, 211 .

26. Hirschfelder, J. O.; Curtiss, C. F.; Bird, R. B. Molecular Theory of Gases and Liquids; Wiley: New York, 1967; see p 168 for the combining rules, pp. $1110-1112$ for $D$ and $1212-1214$ for $\sigma$,

27. Lim, K. F. J. Chen. Phys. 1994, J00, 7385.

28. Huber, K. P.; Herzberg, G. Constants of Diatomic Molectles; Van Nostrand Reinhold: New York, 1979.

29. Gear, C. W. Numerical Initial Valne Problems in Ondinary. Differential Equations; Prentice-Hall: New York, 1971.

30. MATH/LIBRARY, Fortran Subroutines for Mathematical Applications; IMSL: Houston, $1989 ; \mathrm{p} 640$.

31. Shi, J.; Barker, J. R. J. Chem. Phys. 1988, 88, 6219. 